\title{
Electromyographic study on the sternocleidomastoid and pectoralis major muscles during respiratory activity in humans
}

\author{
NEPOMUCENO, V. R. ${ }^{*}$, NEPOMUCENO, E. M. ${ }^{2}$, REGALO, S. C. H. ${ }^{3}$, \\ CERQUEIRA, E. P. ${ }^{4}$ and SOUZA, R. R. ${ }^{5}$
}

\author{
${ }^{1}$ Universidade Federal do Tocantins - UFT, Av. NS 15 ALCNO 14, CEP 77020-210, Palmas, TO, Brazil \\ ${ }^{2}$ Universidade Luterana do Brasil - ULBRA, Av. Teotônio Segurado, 1501, CEP 77019-900, Palmas, TO, Brazil \\ ${ }^{3}$ Department of Morphology, Physiology and Basic Pathology, Ribeirão Prêto School of Dentistry, University of \\ São Paulo - USP, Av. do Café, s/n, Monte Alegre, CEP 14040-904, Ribeirão Preto, SP, Brazil \\ ${ }^{4}$ Department of Anatomy, Institute of Biomedical Science, University of São Paulo - USP, Av. Lineu Prestes, 2415, \\ Ed. Biomédicas III, CEP 05508-900, São Paulo, SP, Brazil \\ ${ }^{5}$ Faculty of Biological Sciences and Health, University of São Judas Tadeu - USJT, R. Taquari, 546, Mooca, CEP \\ 03166-000, São Paulo, SP, Brazil \\ *E-mail: victorn@uft.edu.br
}

\begin{abstract}
Introduction: This study aimed to evaluate the simultaneous and maximum activities of the sternocleidomastoid (SCM) and pectoralis major (PM) muscles, to determine how the two types of breathing patterns (normal and forced) can affect these activities, and to verify which of these muscles could be used to establish an evaluation protocol for patients undergoing mechanical ventilation. Methods: Eleven healthy men, aged 18 to 25 years, participated in this study. The individuals remained in supine position using a respiratory belt to monitor both inspiratory and expiratory phase during shifts in the rib cage, performing three repetitions for the normal and forced respiratory movements, while keeping the breathing rhythm with a standard metronome. Electromyographic signals were captured using bipolar surface electrodes placed on the lower third of the SCM muscle and on the lower PM muscle fibers. Electromyographic signals were analyzed and the root mean square (RMS) values were calculated for a complete respiratory cycle. The EMG values were analyzed using the Bonferroni test for multiple comparisons. The homogeneity of variances was verified using the logarithmic transformation (LOG). The level of statistical significance was set at 5\% (SPSS 19.0). Results: The values showed that there are significant differences between the EMG values of the SCM muscle during normal and forced respiration and the EMG values of the ECM and PM muscles during forced respiration. Conclusion: These results showed that the SCM muscle can be an indicator for the development of parameters to be used in the analysis of patients with respiratory failure.
\end{abstract}

Keywords: electromyography, sternocleidomastoid muscle, pectoralis major muscle, respiratory activity.

\section{Introduction}

The respiration accessory muscles have been widely studied so that further information on their actions can be obtained, considering that there is some controversy as to their function, the phase of the respiratory cycle in which they are more active, the best body position for these muscles to function more effectively, and the type of respiration that would increase their activity (KENDALL, MCCREARY and PROVANCE, 1995).

Surface electromyography of the respiratory muscles has been used for many years to investigate their actions during various types of respiration patterns (TROYER and SAMPSON, 1982; GANDEVIA, MCKENZIE and PLASSMAN, 1990; PLASSMAN, LANCING and FOTI, 1987) in different pulmonary volumes (CALLA, EDYVEAN and ENGEL, 1992; BRANCATISANO, ENGEL and LORING, 1993); in fatigue conditions (SUZUKI, SUZUKI and OKUBO, 1991; JANSSENS, BRUMAGNE, MCCONNELL et al., 2013); in different postures (TROYER and SAMPSON 1982; RIMMER, FORD and WHITELAW, 1995; KERA and MARUYAMA, 2005); and after muscle training in patients with chronic obstructive pulmonary diseases (KIM, BYUN, LEE et al., 2012).
One of these muscles is the sternocleidomastoid muscle, which not only acts with other muscles to flex the neck and extend the head but it is also considered the main accessory muscle of inspiration, acting mainly during moderate and deep inspiration, where some activity during inspiration at rest can be observed, promoting an increase in the anterior posterior diameter of the chest wall (COSTA, VITTI, TOSELLO et al., 1994; CASAS, PAVÍA and MALDONADO, 2003; SHADGAN, GUENETTE, SHEEL et al., 2011).

Another muscle that plays an important role in respiration is the pectoralis major (PM) (GOSS, 1988). It is considered the third most important accessory muscle of inspiration. It remains active during the forced inspiratory movements, acting when the arms and shoulders are fixed, and pulls the insertion toward the origin with compressive force applied to the anterior chest, raising the ribs and sternum and increasing the anteroposterior diameter of the thorax (PETTERSEN, 2006).

In the future, the electromyographic analysis of the respiration muscles may be a very important non-invasive clinical tool, particularly in rehabilitation, to be used by 
physiotherapists and doctors in the evaluation of respiratory mechanics of patients in Intensive Care Unit (ICU), as they would assist in the indication for intubation, ventilator weaning, and extubation of those with respiratory failure (CERQUEIRA and GARBELLINI, 1999).

The main purpose of this study was to conduct an electromyographic analysis of the SCM and PM muscles during the respiratory activity in humans, thus to contribute for the development of an evaluation protocol of the EMG activity of these muscles in patients with respiratory failure and/or in those dependent on mechanical ventilation.

\section{Materials and Methods}

Eleven healthy male subjects volunteered for this study. Mean \pm SD age, weight and height were $20.36 \pm 2.24$ years, $86.72 \pm 10.07 \mathrm{~kg}$, and $189.27 \pm 5.71 \mathrm{~cm}$, respectively. All subjects had no history of respiratory pathologies or impairment of the skeletal muscle system.

The research was approved by the Research Ethics Committee of the Institute of Biomedical Science- ICB (case N. 548/2004). All volunteers agreed to participate by providing their free and informed consent according to resolution 196/96 of the Health National Council.

Surface bipolar active electrodes $(\mathrm{Ag} / \mathrm{AgCl})$ (Biologic Systems Corp) were positioned on the skin over the bellies of the SCM and PM muscles, oriented parallel to the muscle fibers, and fixed with adhesive tape (CREMER SA Têxtil). The skin was shaved and scrubbed with alcohol before electrode placement; a conductive gel was used to reduce skin impedance. With the volunteer in supine posture, the location of the electrodes was determined by the identification of the muscle bellies on the right side of the body. The individual was asked to perform isometric contractions against stable resistance, which were determined as follows: for the SCM- in the distal third of the muscle belly; and the PM - $2 \mathrm{~cm}$ above the center of the nipple, laterally. A reference electrode was placed around the ulnar styloid process of the right upper limb.

The myoelectrical signals were processed using a portable Bagnoli - 2 EMG Systems (DELSYS Inc. - Boston), with input impedance higher than $100 \mathrm{M} \Omega$, common-mode rejection ratio (CMRR) greater than 50.000: 1-50 Hz, amplified $(200 \mathrm{mV} / \mathrm{div})$. The raw EMG signals were filtered by a cutoff frequency of $16 \mathrm{~Hz}$ and $800 \mathrm{~Hz}$ and stored in the computer with a sampling rate of $2.000 \mathrm{~Hz}$ (scan rate of $240 \mathrm{~ms} / \mathrm{div}$ ), using a 12 bit resolution analogue to digital converter card (Lynx Tecnologia Eletrônica Ltda) for further analysis. The pneumotrace respiratory belt (Gould Instrument Systems) was placed at the level of the armpit of the volunteers, which would respond linearly to changes in the thoracic circumference, enabling the identification of the beginning of inspiration (I) and expiration (E) for 10 seconds. These activities were carried out by volunteers, with a quiet breathing through the nose $($ normal $=\mathrm{N}$ ), followed by a deep maximum breathing (forced $=F$ ), inspiring through the nose and exhaling through the mouth, synchronized with a mechanical device called metronome (KORG MA - 30 - Taiwan), with a standard frequency of 45 beats $/ \mathrm{min}$. With these markings (frequency and sound signals) we wanted to represent the rhythm of the breathing movements in $1: 2$ ratio; 1 corresponding to inspiration
(0.8-1.2 seconds), and 2 corresponding to expiration (1.6 -2.4 seconds) (AZEREDO, 2002a, b; ÂNGELO, ABREU, SANTOS et al., 2000).

An electromyograph and a pneumotrace respiratory belt device were linked to a CompaqPC 486/DX4 - 100 $\mathrm{MHz}$, using the AqDados software for processing, and the AqAnalysis for the analysis of electromyographic recordings (Lynx Tecnologia Eletrônica - Ltda). The EMG values were calculated for a 10 -second period. The mean values of the eleven volunteers were obtained from the sum of the means of the three trials of each subject for a further statistical analysis. The electromyographic values were analyzed using analysis of variance with three factors: muscle with two levels (SCM and PM), respiratory phase with two levels (inspiration and expiration), and a repeated measure to compare the two breathing patterns (normal and forced). Bonferroni's test was used for multiple comparisons. The homogeneity of variances was verified using the logarithmic transformation (LOG). The level of statistical significance was set at $\mathrm{p}<0.05$.

\section{Results}

The results of this study are shown in Table 1 and Figure 1, which describe the mean values obtained for each phase ( $\mathrm{I}$ and $\mathrm{E}$ ) and type $(\mathrm{N}$ and $\mathrm{F})$ of the respiratory cycle for the eleven volunteers.

Table 1 shows the mean values of the electromyographic activity, standard deviation and standard error in RMS $(\mu \mathrm{V})$ of both muscles (SCM and PM) during the types and phases of the respiratory cycle.

Some significant differences were observed between the EMG values of the SCM muscles obtained during $\mathrm{N}$ and $F$ respiration $(\mathrm{p}<0.05)$. During $\mathrm{F}$ respiration, the EMG values of the SCM and PM muscles presented significant differences $(\mathrm{p}<0.05)$.

Figure 1 shows the mean values and the standard error of the electromyographic activities of muscles SCM and PM for the types and phases of the respiratory cycle.

\section{Discussion}

The findings of the present study showed low EMG activity of the SCM and PM muscles throughout the normal respiratory cycle. However, it is not possible to suggest that lower activities occur because these muscles really participate in the respiratory activity or because this activity relates to the muscular tonus, which is defined as a certain tension present

Table 1. Muscular activity (RMS) during the respiratory cycle, mean values and standard error (SE). Respiration phases: Inspiration (I) and Expiration (E) and Types: Normal (N) and Forced (F).

\begin{tabular}{ccccc}
\hline Muscles & Types & Phases & Mean & SE \\
\hline SCM & N & I & 4.08 & 0.61 \\
& & E & 3.59 & 0.30 \\
& F & I & 8.51 & 1.11 \\
& & E & 5.74 & 0.65 \\
PM & N & I & 4.57 & 0.33 \\
& & E & 4.59 & 0.34 \\
& F & I & 5.18 & 0.45 \\
& & E & 4.97 & 0.40 \\
\hline
\end{tabular}




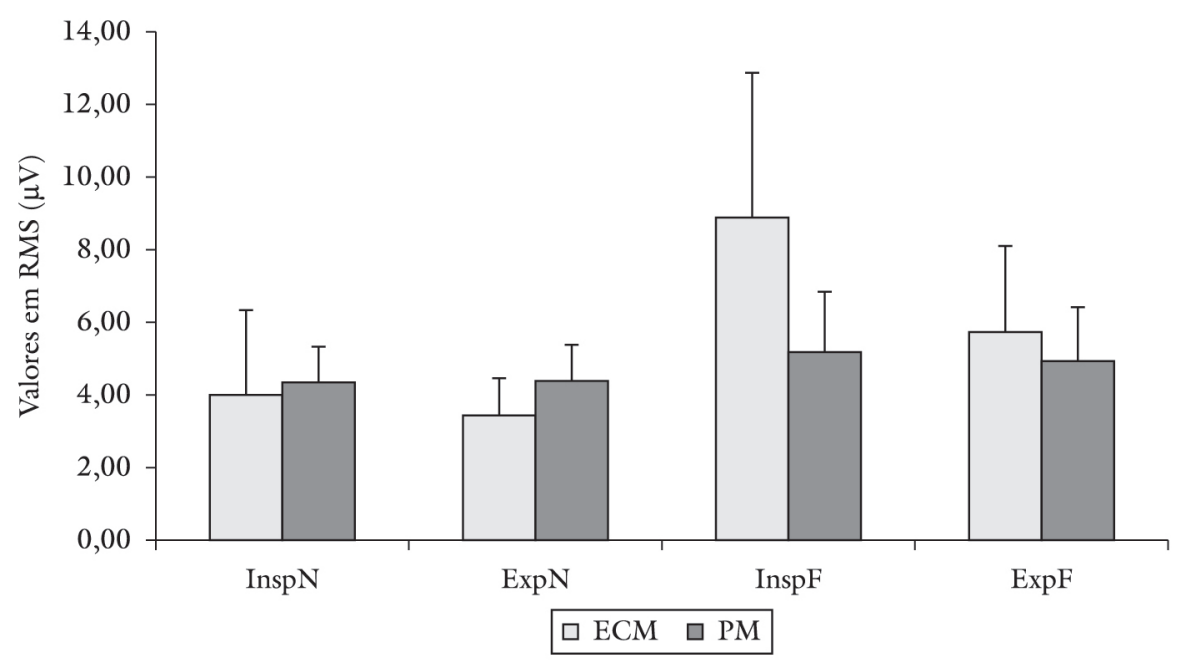

Figure 1. Mean values of the electromyographic activities of the SCM and PM muscles during the normal and forced respiration cycles: SCM and PM muscles in inspiratory phase and normal respiration cycle (InspN); SCM and PM muscles in expiratory phase and normal respiration cycle $(\operatorname{ExpN}) ; S C M$ and PM muscles in inspiratory phase and forced respiration cycle (InspF); SCM and PM muscles in expiratory phase and forced respiration cycle $(\mathrm{ExpF})$.

in the striated skeletal muscles, even at rest (BASMAJIAN and DE LUCA, 1985).

As described in Table 1, the SCM muscle had greater activity during the inspiratory phase and forced respiration, confirming the findings of Jones, Beargie and Pauly (1953), Plassman, Lancing and Foti (1987), Gandevia, Mckenzie and Plassman (1990), Costa, Vitti, Tosello et al. (1994) and Legrand, Schneider, Gevenois et al. (2003). Some hypotheses to explain this finding are: 1) greater SCM muscle activity during forced inspiration occurs because, during the respiratory effort, the pulmonary ventilation increases, causing the main respiratory muscles to undergo a mechanical disadvantage, which in turn, places a burden on the accessory muscles (TOKIZANE, KAWAMATA and TOKIZANE, 1952; CAMPBELL, 1958; COSTA, VITTI, TOSELLO et al., 1994); 2) the volunteers who obtained higher RMS values had a costal respiratory pattern (subjects with a predominance of thoracic expansion over abdominal during the inspiratory movements) and not a diaphragmatic or mixed type; 3 ) the volunteers who presented a costal respiratory type, needed increased amplitude of movements of the ribcage, which contributes to the elevation of the sternum, acting synergistically on the neck muscles (JONES, BEARGIE and PAULY, 1953; COSTA, VITTI, TOSELLO et al., 1994); 4) this muscle can still be more active according to the ventilatory pattern, degree of alertness, muscle strength, resistance to air flow and complacency of the lungs and the thoracic wall (KENDALL, MCCREARY and PROVANCE, 1995).

Other authors reported the activity of the SCM muscle in inspiration at rest (COSTA, VITTI, TOSELLO et al., 1994; RATNOVSKY, ZARETSKY, SHINER et al., 2003), which was not found in our study.

There was also greater activity in the PM muscle during forced inspiration (Table 1), in accordance with the findings of Goss (1988), Kendall, Mccreary and Provance (1995) and Guyton and Hall (2002). However, the activity of the PM muscle during forced inspiration and expiration was lower in comparison with the activity of the SCM muscle in the same phases and types of respiration. The SCM muscle performs the respiratory movements while the PM muscle stabilizes the rib cage. The activity of the PM muscle does not differ much as to the normal and forced respiration (CALLA, EDYVEAN and ENGEL, 1992).

As it was shown in the present study, the PM muscle presented low electromyographic activity during forced form and the inspiration and expiration phases of the respiratory cycle, which were similar to the results of Plassman, Lancing and Foti (1987) and Cerqueira and Garbellini (1999).

Other authors found higher values for the electromyography activity in the PM muscle during normal inspiration, confirming our findings. These authors attributed this increased activity of the PM muscle to the stabilization and elevation of the rib cage. However, in our study, a greater activity of the PM muscle was observed during normal expiration when compared to the SCM muscle in the same phase and respiration type (CERQUEIRA and GARBELLINI, 1999).

Azeredo (2002a) only considers the pectoralis minor, and not the pectoralis major muscle, as an accessory muscle for respiration with proved inspiratory function, which is inconsistent with our findings.

We found low RMS values of the EGM signals for SCM and PM muscles during normal expiration. This is explained because the expiration is predominantly passive; therefore, lower values are expected (JONES, BEARGIE and PAULY, 1953; RATNOVSKY, ZARETSKY, SHINER et al., 2003).

The electromyographic values of the SCM and the PM muscles during forced expiration were also low, whereas the abdominal muscles are responsible for this movement, as previously described by Goss (1988) and Guyton and Hall (2002).

However, in individuals with cervical spinal injury (C5C8) who are capable of inspiring via an active control of the diaphragm muscle and produce weak expiratory efforts due to the inactivity of the abdominal muscles, coughing 
is performed through an active process that involves contraction of the clavicular portion of the pectoralis major. Under these conditions, the action of this muscle compresses the upper chest to produce compression and expulsion of air (BOLSER and REIER, 1998).

The SCM and PM muscles may be considered as accessory muscles for respiration, as in this study, we observed that these muscles were more active during forced inspiration.

Patients with symptoms of respiratory muscle dysfunction, e.g., making use of the accessory muscles, with abdominal movement and paradoxical thoracic movement, tachypnea and dyspnea, often need ventilatory support (COSTA, VITTI, TOSELLO et al., 1994; AZEREDO, 2002a, b; RIBEIRO, MARCHIORI and SILVA, 2002; RATNOVSKY, ZARETSKY, SHINER et al., 2003). Therefore, the identification of strategies to reduce the time of mechanical ventilation and to re-establish ventilatory autonomy becomes a priority, so protocols would be indicated and effective (GOLDWASSER, 2000). If the SCM and the PM muscles of patients undergoing this type of therapy were evaluated using the electromyography, the ventilation parameters could be controlled more accurately, with short time, and therefore, would minimize the atrophy caused by the inactivity of the respiratory muscles. Other clinical parameters should also be considered, such as the improvement of basic pathology, of radiology, and of the level of consciousness of the patient and others.

\section{Conclusion}

The results showed that the SCM and the PM muscles presented EMG activity during the different phases and types of the respiratory cycle, which can influence the activity of both muscles. Thus, the SCM muscle can be an indicator for the elaboration of an evaluation protocol to analyze the respiratory pattern associated with the activity of the respiratory muscles in patients with respiratory dysfunction. Further studies should be carried out to establish evaluation protocols for other clinical conditions in volunteers of different genders and age groups.

\section{References}

ÂNGElO, MAF., ABREU, R., SANTOS, ANC., PINHEIRO, BDV., SAD, EF., TEIXEIRA JÚNIOR, JF., REIS, MAS., PIZZIOLO, MCM., MACHADO, MDGR., BOTONI, FA. and ROCHA, P. Métodos essenciais de ventilação mecânica. In: Sociedade Brasileira de Pneumologia e Tisiologia. II Consenso Brasileiro de Ventilação Mecânica. Journal of Pneumology, 2000, vol. 26, Suplemento 2, Cap. 2, p. 8.

AZEREDO, CAC. Fisioterapia respiratória moderna. 4th. ed. São Paulo: Manole, 2002a.

AZEREDO, CAC. Técnicas para o desmame no ventilador mecânico. São Paulo: Manole, 2002b.

BASMAJIAN, JV. and DE LUCA, CJ. Muscles alive: their functions revealed by electromyography. 5th ed. Baltimore: Williams \& Wilkins, 1985.

BOLSER, CD. and REIER, PJ. Inspiratory and expiratory patterns of the pectoralis major muscle during pulmonary defensive reflexes. Journal of Applied Physiology, 1998, vol. 85, n. 5, p. 1786-1792. PMid:9804582.
BRANCATISANO, A., ENGEL, LA. and LORING, SH. Lung volume and effectiveness of inspiratory muscles. Journal of Applied Physiology, 1993, vol. 4, n. 2, p. 688-694.

CALLA, SJ., EDYVEAN, J. and ENGEL, LA. Chest wall and trunk muscle activity during inspiratory loading. Journal of Applied Physiology, 1992, vol. 73, n. 6, p. 2373-2381. PMid:1490946.

CAMPBELL, EJ. Disordered pulmonary function in emphysema. Postgraduate Medical Journal, 1958, vol. 34, n. 387, p. 3038. PMid:13494262 PMCid:PMC2501027. http://dx.doi. org/10.1136/pgmj.34.387.30

CASAS, A., PAVÍA, J. and MALDONADO, D. Respiratory muscle disorders in chest wall diseases. Archivos de Bronconeumología, 2003, vol. 39, n. 8, p. 361-366. PMid:12890404.

CERQUEIRA, EP. and GARBELLINI, D. Electromyographic study of the pectoralis major, serratus anterior and external oblique muscles during respiratory activity in humans. Electromyography and Clinical Neurophysiology, 1999, vol. 39, n. 3, p. 131-137. PMid:10228878.

COSTA, D., VITTI, M., TOSEllo, DO. and COSTA, RP. Participation of the sternocleidomastoid muscle on deep inspiration in man: an electromyographic study. Electromyography and Clinical Neurophysiology, 1994, vol. 34, n. 5, p. 315-320. PMid:7956883.

GANDEVIA, SC., MCKENZIE, DK. and PLASSMAN, BL. Activation of human respiratory muscles during different voluntary manoeuvres. Journal of Physiology, 1990, vol. 428, p. 387-403. PMid:2231418 PMCid:PMC1181653.

GOLDWASSER, R. Desmame. In: Sociedade Brasileira de Pneumologia e Tisiologia. II Consenso Brasileiro de Ventilação Mecânica. Journal of Pneumology, 2000, vol. 26, Suplemento 2, Cap. 14, p. 55

GOSS, C. M. Anatomia. 29th. ed. Rio de Janeiro: Guanabara Koogan, 1988.

GUYTON, AC. and HALL, JE. Tratado de fisiologia médica. 10th. ed. Rio de Janeiro: Guanabara Koogan, 2002.

JANSSENS, L., BRUMAGNE, S., MCCONNELL, AK., RAYMAEKERS, J., GOOSSENS, N., GAYAN-RAMIREZ, G., HERMANS, G. and TROOSTERS, T. The assessment of inspiratory muscle fatigue in healthy individuals: a systematic review. Respiratory Medicine, 2013, vol. 107, n. 3, p. 331-346. PMid:23273596. http://dx.doi.org/10.1016/j.rmed.2012.11.019

JONES, DS., BEARGIE, RJ. and PAULY, JE. An electromyographic study of some muscles of costal respiration in man. Anatomical Record, 1953, vol. 117, n. 1, p. 17-24. PMid:13092550. http:// dx.doi.org/10.1002/ar.1091170103

KENDALL, FP., MCCREARY, EK. and PROVANCE, PG. Músculos: provas e funções. 4th. ed. São Paulo: Manole, 1995.

KERA, T. and MARUYAMA, H. The effect of posture on respiratory activity of the abdominal muscles. Journal of Physiological Anthropology and Applied Human Science, 2005, vol. 24, n. 4, p. 259-265. PMid:16079565. http://dx.doi.org/10.2114/ jpa.24.259

KIM, KS., BYUN, MK., LEE, WH., CYNN, HS., KWON, OY. and $\mathrm{YI}, \mathrm{CH}$. Effects of breathing maneuver and sitting posture on muscle activity in inspiratory accessory muscles in patients with chronic obstructive pulmonary disease. Multidisciplinary Respiratory Medicine, 2012, vol. 7, n. 1, p. 9. PMid:22958459 PMCid:PMC3436653. http://dx.doi.org/10.1186/2049-69587-9

LEGRAND, A., SCHNEIDER, E., GEVENOIS, PA. and TROYER, A. Respiratory effects of the scalene and sternomastoid muscles in humans. Journal of Applied Physiology, 2003, vol. 94, n. 4, p. 1467-1472. PMid:12626472. 
PETTERSEN, V. Preliminary findings on the classical singer's use of the pectoralis major muscle. Folia Phoniatrica et Logopaedica, 2006, vol. 58, n. 6, p. 427-439. PMid:17108700. http://dx.doi. org/10.1159/000095003

PLASSMAN, BL., LANCING, RW. and FOTI, K. Inspiratory muscle responses to airway occlusion during learned breathing movements. Journal of Neurophysiology, 1987, vol. 57, n. 1, p. 274 288. PMid:3559676.

RATNOVSKY, A., ZARETSKY, U., SHINER, RJ. and ELAD, D. Integrated approach for in vivo evaluation of respiratory muscles mechanics. Journal of Biomechanics, 2003, vol. 36, n. 12, p. 17711784. http://dx.doi.org/10.1016/S0021-9290(03)00232-X

RIBEIRO, EC., MARCHIORI, SC. and SILVA, AMT. Electromyographic analysis of trapezius and sternocleidomastoideus muscles during nasal and oral inspiration in nasal - and mouth - breathing children. Journal of Electromyography and Kinesiology, 2002, vol. 12, n. 4, p. 305- 316. http://dx.doi. org/10.1016/S1050-6411(02)00025-1

RIMMER, KP., FORD, GT. and WHITELAW, WA. Interaction between postural and respiratory control of human intercostals muscles. Journal of Applied Physiology, 1995, vol. 79, n. 5, p. 15561561. PMid:8594013.
SHADGAN, B., GUENETTE, JA., SHEEL, AW. and REID, WD. Sternocleidomastoid muscle deoxygenation in response to incremental inspiratory threshold loading measured by near infrared spectroscopy. Respiratory Physiology \& Neurobiology, 2011, vol. 178, n. 2, p. 202-209. PMid:21684356. http://dx.doi.org/10.1016/j. resp.2011.06.001

SUZUKI, S., SUZUKI, J. and OKUBO, T. Expiratory muscle fadigue in normal subjects. Journal of Applied Physiology, 1991, vol. 70, n. 6, p. 2632-2639. PMid:1885458.

TOKIZANE, T., KAWAMATA, $\mathrm{K}$. and TOKIZANE, $M$. Electromyography studies on the human respiratory muscles: studies on the activity pattern of neuro-muscular units. The Japanese Journal of Physiology, 1952, vol. 2, n. 3, p. 232-247. PMid:14927261.

TROYER, A. and SAMPSON, MG. Activation of the parasternal intercostais during breathing efforts in human subjects. Journal of Applied Physiology: Respiratory, Environmental and Exercise Physiology, 1982, vol. 52, n. 3, p. 524-529. PMid:6461619.

Received October 12, 2013 Accepted June 15, 2014 